\title{
Discussions on Field Management of Ginseng Cultivation and Pest Control
}

\author{
Shijie Wang ${ }^{1,2}$, Fengbo $\mathrm{Han}^{2}$, Yunsheng $\mathrm{YaO}^{2}$, Rusheng $\mathrm{Li}^{2}$, Xiaoli Jiang ${ }^{1}$, \\ Gang $\mathrm{Li}^{1}$, Yan Zhao ${ }^{3}$ \\ ${ }^{1}$ Jilin Academy of Agricultural Sciences, Changchun Jilin, 130033, China \\ ${ }^{2}$ School of Traditional Chinese medicine, Jilin Agricultural Science and Technology University, Jilin \\ Jilin, 132101, China \\ ${ }^{3}$ School of Chinese Medicinal Materials, Jilin Agricultural University, Changchun Jilin, 130118, China
}

Key words: Ginseng cultivation, Field management, Pest control.

\begin{abstract}
The state has started to attach importance to ginseng planting work in the process of economic development and require the conformance of ginseng planting quality to relevant standards. As ginseng planting will cause serious damage of land resources, people transform it into artificial cultivation. This requires ginseng cultivation personnel to conduct field management and pest control work well and guarantee better improvement of ginseng cultivation quality.
\end{abstract}

\section{Introduction}

Field management and pest control problems often occur in the process of ginseng cultivation, which influence the quality of ginseng planting. Relevant administrative staff must attach importance to such work and take effective measures to optimize field management and pest control mode of ginseng cultivation and lay a good foundation for its development.

\section{Requirements for ginseng growth environment}

In the process of ginseng cultivation, relevant administrative staff must have a comprehensive understanding of its requirements for growth environment and guarantee the conformance to relevant provisions. Specific requirements of ginseng for growth environment include the following:

First, soil environment.

According to relevant researches, sandy soil is appropriate for ginseng growth mainly because it is deep and loose and has strong water permeability and good drainage ability. Meanwhile, alkaline soil is also appropriate for ginseng planting, which is good for improving its growth efficiency.

Second, illumination environment.

Ginseng prefers to shady area in actual growth process. It cannot be exposed to sunshine directly. Only scattered dim light is allowed. Once a ginseng is exposed to bright light, the plant will be short and the leaf of ginseng will show yellow spots, disease or death trend, thus producing adverse influence on it. Inadequate illumination will cause long and thin plant and strong green leaf. Therefore, illumination environment for the growth of ginseng should be adjusted carefully so as to guarantee its growth health.

Third, water resource environment.

Ginseng is very selective about water resources during growth. Though ginseng is hydrophile, excessive moisture will cause water logging phenomenon and decomposition of ginseng root and produce adverse influence on the growth of ginseng. Inadequate moisture will cause drying of ginseng and reduction of its yield. Therefore, it is required to control soil moisture strictly in the process of ginseng cultivation and avoid influencing economic benefit of ginseng cultivation industry. 
Forth, ambient temperature.

Ginseng likes cold conditions. Ambient temperature cannot be excessive and should be controlled at about $18^{\circ} \mathrm{C}$ in the growth or development process so as to guarantee the growth quality of ginseng. Once the temperature is more than $30^{\circ} \mathrm{C}$ or lower than $10^{\circ} \mathrm{C}$, ginseng will be dormant. For this reason, ginseng can get through cold winter normally. Even when the temperature is lower than $40^{\circ} \mathrm{C}$, ginseng will not die. Ginseng is sprouting in spring. Large fluctuation of temperature will produce adverse influence on it.

Fifth, fertilizer control.

Ginseng is a fertilizer-liking plant. The use of organic or inorganic fertilizer can effectively improve the growth efficiency of ginseng. However, non-rotten manure cannot be used. The use of such fertilizer will cause rootlet burning or rotted root of ginseng in the growth process and incur serious economic losses to ginseng cultivation industry.

\section{Ginseng cultivation and field management technology}

Ginseng cultivation management technicians must comprehensively master key points of cultivation management technology and guarantee better improvement of their own work in the process of work implementation and then improve the quality of finished products of ginseng. Specific cultivation management technologies include the following:

\section{A. Selection and management of land for ginseng growth}

Land selection and management is most important for the growth of ginseng.

First, relevant technicians must select broad-leaved forest and shrubwood for planting according to growth demands of ginseng in the process of land selection. Meanwhile, the soil should be rich in phosphorus and potassium. Meanwhile, soil type should better be forest spodosols or live loess so as to guarantee better growth of ginseng.

Second, relevant administrative staff should conduct land clearing work well after land selection. The time for clearing should be established after autumn begins. It is required to first cut down small trees, remove tree root and then clear bark and weed etc. Weed can be burned after drying, which can not only guarantee the cleanness of land, but also add some fertilizers to soil.

Third, administrative staff should conduct land consolidation, turn over humus contained in soil to the upper layer and then process large clod. Meanwhile, tree root and pests should be cleared with professional tool to avoid influencing ginseng growth.

Finally, disinfection work should be conducted well and Dijunling should be used for disinfection. Meanwhile, importance should be attached to bedding work. Bedding direction should be selected scientifically and reasonably according to terrain analysis of ginseng planting area and then bedding work should be implemented. Some service passages should be set up in the furrow so as to guarantee the convenience of work and improve the efficiency of ventilation and transmittance. In the design process of follow, its middle should be higher than both sides and meanwhile drainage ditch should be set up around the furrow to avoid water logging in seasons with large rainfall. In addition, sunshade should be set up above furrow to avoid adverse influence of direct sunlight on ginseng.

\section{B. Management technology before and after ginseng sowing}

Relevant administrative staff should attach importance to the mastery of management technology and guarantee effective implementation of management work before and after ginseng sowing.

First, administrative staff should attach importance to germination acceleration before sowing. There are two ways for germination acceleration of ginseng: first, outdoor germination; second, indoor germination. Outdoor germination requires leeward and apricus places. First, dig a $20 \mathrm{~cm}$ hole on flat ground with professional tool, the specific length and width of which should be determined according to practical situation and within the specified scope. Then, prepare a wooden case with the same size as the hole, put it into the hole and dig a drainage ditch. This can guarantee the 
improvement of outdoor germination quality. Relevant administrative staff should soak ginseng seeds in water at normal temperature for 24 to 48 hours, water them after taking them out from water, then mix them with 3 times of river sand (pay attention to the uniformity of stirring), finally put them into the hole and cover the soil layer. The thickness of soil layer should be about $15 \mathrm{~cm}$.Moreover, relevant administrative staff can cover with a layer of waterproof configuration so as to prevent exposure to the sun or soaking by rain.

Second, relevant administrative staff should select sowing time reasonably before sowing, which should better be in spring, summer and autumn. The time for ginseng sowing in spring can be mid March. After the implementation of germination work, seeds can be sowed. The time for sowing in autumn should better be late October. Seeds can be sowed after germination or directly sowed without germination. Currently, many ginseng cultivation personnel choose to seed in summer approximately between late July and late August. Seeds collected in the current year can be directly used for sowing.

Third, relevant management personnel must select sowing method scientifically and reasonably in the sowing process. Generally, there are three sowing methods of ginseng: spaced sowing, sowing in line and broadcast sowing. Spaced sowing of ginseng seeds means sowing at an interval of $3 \mathrm{~cm}$ between each two seeds. Its advantage is that it can guarantee the uniformity of ginseng growth and effectively save ginseng seeds. However, it has a waste of human resources. Broadcast sowing can effectively save human resources, but it wastes seeds and therefore produces adverse influence on economic benefit. Sowing in line is between them. Currently, broadcast sowing method is mostly used for sowing in ginseng cultivation industry.

Forth, ginseng transplanting work is an important link. Relevant administrative staff must transplant them after seedlings grow up to a certain extent. Transplanting is generally conducted in early October, i.e. before freeze. However, administrative staff should master the time flexibly according to local climatic conditions due to differences of climatic conditions in each region of the country. Meanwhile, lifting of seedlings should be conducted first in the transplanting process. Young seedlings without pest should be selected and classified into large, middle and small seedlings after lifting so as to guarantee the scientificity of transplanting. Flat planting or oblique planting can be considered for the selection of transplanting method ${ }^{[2]}$.

\section{Ginseng field management technology}

Relevant administrative staff should conduct field management work well after ginseng sowing to avoid influencing the development of ginseng.

First, administrative staff should clear cold-proof grass in the field when ginseng spores have not sprouted and meanwhile loosen the soil. Attention should be paid not to damage ginseng root during loosening. After soil loosening for the first time, relevant administrative staff should loosen the soil shallowly for three times each year. Moreover, they should also disinfect furrow surface fully and guarantee the improvement of pest control efficiency. Second, administrative staff should divide the whole ginseng cultivation land into several areas and conduct flower bud picking work based on areas. Third, they should loosen the soil and extirpate weed in the furrow periodically and guarantee effective improvement of field management efficiency. Finally, administrative staff should conduct fertilization work well and determine fertilizing amount according to ginseng growth demands. Excessive fertilization is not allowed so as to avoid root hair burning. In addition, they should also protect ginseng against the cold and guarantee the rationality of ginseng growth environment.

\section{Ginseng pest control technology}

\section{Damping-off prevention and treatment method}

Ginsengs often contract damping-off in the growth process. The cause of such virus is imperfect fungi in fungus. Incidence time is often during seedling emergence and leaf expansion. To prevent such 
virus better, relevant administrative staff should conduct field management work well, carry out soil loosening activity periodically and increase the temperature of soil for ginseng growth. After discovering any ginseng affected by such virus, administrative staff should remove it and gather all ill ginseng seedlings with professional tool and burn them with big fire so as to avoid the spread of disease. Meanwhile, they should also use Likuling to prevent recurrence of damping-off ${ }^{[3]}$.

\section{Prevention and treatment method of black spot}

To prevent and cure black spot effectively, administrative staff should conduct seedling treatment, field management and drug therapy. For seedling treatment, administrative staff should use formalin $1 \%$ solution for 15-minute soaking of ginseng seedling and implement the work of germination acceleration and sowing after drying. After seedlings come up out of the ground, they can spray polyoxins above to guarantee effective prevention of black spot. Field management. Administrative staff should process ill ginseng branches and leaves in time and burn them after autumn to prevent virus from living through the winter. Drug therapy. Ginsengs should generally be subject to medical prevention for the first time in June each year. Then, drugs should be sprayed once every 8 days. The most common drugs for black spot of ginseng are Bordeaux mixture and Amobam etc. Administrative staff should use drugs reasonably according to relevant provisions.

While using drugs for black spot, administrative staff can use drugs alternately to avoid antibody of virus. Meanwhile, they should shorten the interval time of drug spraying in cloudy and rainy weather in summer to avoid the loss of drug function due to rain wash.

\section{Epidemic prevention work}

In the process of ginseng planting, relevant administrative staff must attach importance to epidemic prevention work. Amobam drug can be used for epidemic prevention and the multiple of its liquid is 800 to 1000 . In cloudy and rainy weather in summer, the times of drug spraying should be increased to guarantee the improvement of efficiency of epidemic prevention.

\section{Erythroderma prevention work}

Ginseng erythroderma will cause serious harm to its growth and make ginseng have yellowed root bark and hard cuticle. Ginseng with mild infection can recover slowly. However, ginseng with serious infection will have cracks and even dead root hair. Thus, effective growth of ginseng cannot be guaranteed. After atrophy of leaf, root hair will decay. Therapy method of ginseng erythroderma: administrative staff should turn over loess below black soil layer with professional tool and guarantee the mixing uniformity of black soil and yellow soil. Meanwhile, live loess can be added to black soil directly. After the mixing of black soil and yellow soil, administrative staff should pay attention to drainage situation and implement soil loosening work periodically. In the process of prevention and treatment of ginseng erythroderma with drugs, relevant administrative staff should soak seeds in Hongpiling during transplanting. This can effectively improve the effect of prevention and treatment which can even be up to $98 \%$.

\section{Conclusion}

In ginseng cultivation field management and pest control process, relevant administrative staff and technicians should attach importance to their responsibilities, guarantee better implementation and avoid problems adverse to their work. Meanwhile, it is required to attach importance to professional quality of administrative staff and technicians and provide training about professional knowledge for them periodically to guarantee that they can master advanced work skills and implement work according to growth demands of ginseng and lay a foundation for the development of ginseng cultivation industry. 


\section{Acknowledgments}

This paper is a postdoctoral program of Jilin Academy of Agricultural Sciences; the " $12^{\text {th }}$ Five-Year" science and technology research project of Jilin Education Office (111022013033); seed fund project of Jilin Institute of Agricultural Science and Technology (119032014004); project of Jilin Science and Technology Agency (111042014010).

\section{References}

[1] Yu Chunfen. Pollution-free Ginseng Cultivation and Field Management. Jilin Agriculture, 2015(22):98.

[2] Luo Dongjie, Niu Liqiang. High-quality High-yield Cultivation Technology of Platycodon Grandiflorum in the North. Technology Wind, 2013(17):176-176.

[3] Sun Peng, Zhang Jifu, Li Licai et al. Cultivation Technology and Method of Golden Cypress. Ginseng Study, 2013,25(3):59-61. 